\title{
Locally advanced leiomyosarcoma of the spleen. A case report and
} review of the literature

\author{
Paolo Piovanello*1, Vincenzo Viola ${ }^{1}$, Giampaolo Costa1, \\ Massimiliano Carletti ${ }^{1}$, Andrea Cecera ${ }^{1}$, Fabrizio Turchetta ${ }^{1}$, \\ Roberto Iudicone ${ }^{1}$, Giuseppe Catalano ${ }^{1}$, Antonello Santucci ${ }^{1}$, \\ Franco Recchia ${ }^{2}$, Loredana Fiorillo ${ }^{3}$, Maria Antonella Menichella ${ }^{3}$ and \\ Giovanni Baiano ${ }^{1}$
}

\author{
Address: ${ }^{1}$ Department of General and Thoracic Surgery, "San Giovanni di Dio" Hospital - Fondi (Latina), Italy, ${ }^{2}$ Department of Anesthesiology - \\ "San Giovanni di Dio" Hospital - Fondi (Latina), Italy and 33perative Room Nursery, "San Giovanni di Dio" Hospital - Fondi (Latina), Italy \\ Email: Paolo Piovanello* - docpapi@yahoo.com; Vincenzo Viola - docpapi@yahoo.com; Giampaolo Costa - docpapi@yahoo.com; \\ Massimiliano Carletti - docpapi@yahoo.com; Andrea Cecera - docpapi@yahoo.com; Fabrizio Turchetta - docpapi@yahoo.com; \\ Roberto Iudicone - docpapi@yahoo.com; Giuseppe Catalano - docpapi@yahoo.com; Antonello Santucci - docpapi@yahoo.com; \\ Franco Recchia - docpapi@yahoo.com; Loredana Fiorillo - docpapi@yahoo.com; Maria Antonella Menichella - docpapi@yahoo.com; \\ Giovanni Baiano - docpapi@yahoo.com \\ * Corresponding author
}

Published: 28 November 2007

World Journal of Surgical Oncology 2007, 5:135 doi:10.1186/1477-7819-5-135

This article is available from: http://www.wjso.com/content/5///135

(c) 2007 Piovanello et al; licensee BioMed Central Ltd.

This is an Open Access article distributed under the terms of the Creative Commons Attribution License (http://creativecommons.org/licenses/by/2.0), which permits unrestricted use, distribution, and reproduction in any medium, provided the original work is properly cited.

Received: 25 May 2007

Accepted: 28 November 2007

\begin{abstract}
Background: Leiomyosarcomas are rare tumours, predominantly localized in the stomach, small intestine and retroperitoneum. Only one case of primary leiomyosarcoma of the spleen is described in human beings in literature.

Case presentation: We report a case of locally advanced primary leiomyosarcoma of the spleen in a 54 year-old woman, diagnosed only after splenectomy, performed with the suspicion of splenic haematoma.
\end{abstract}

Conclusion: Due to the lack of cases, no specific chemotherapy regimen has been tested to provide a longer survival.

\section{Background}

Leiomyosarcomas are rare tumours, predominantly localized in the stomach, small intestine and retroperitoneum. Only one case of primary leiomyosarcoma of the spleen is described in human beings in literature.

\section{Case presentation}

A 54-year-old Caucasian woman was referred to our department with a history of left-sided abdominal pain, lasting about 8 months. No other signs or symptoms were present at the moment of observation. Past medical history revealed no significant medical problems. Hysterectomy for endometriosis had been performed ten years before admission. No history of carcinogenic exposure was reported. At admission physical examination revealed a palpable spleen $4 \mathrm{~cm}$ below the left costal margin. No hepatomegaly was noted. Laboratory exams showed no alterations, except for mildly elevated lactic acide dehy- 
drogenase (LDH). Chest X-ray showed a normal mediastinum and lung parenchyma. Abdominal US revealed, in the superior portion of the spleen, multiple target-shaped focal lesions, one of these with a large anechoic fluidfilled area. CT scan showed a large, inhomogeneous mass of the spleen, of $10 \times 7 \mathrm{~cm}$ in diameter. This mass was isodense, without enhancement after contrast injection, and had low density fluid-filled areas. The liver parenchyma was normal and no evidence of retroperitoneal lymphadenopathy was found. Emergency laparotomy was performed, due to the suspicion of splenic haematoma. Neither obvious metastases nor hepatic lesions or abdominal fluid were found at laparotomy. An enormous mass of superior portion of the spleen was found, with infiltration of left suprarenal gland and of a portion of diaphragm. Due to the local dissemination a splenectomy and left surrenalectomy were performed, along with a partial diaphragm resection, with a free resection margin of about two centimetres. Splenic vessel lymphadenectomy was also performed. There were no postoperative problems and the patient was discharged on 7th postoperative day. Two different Institution was necessary to obtain the definitive diagnosis. Histological examination showed a spleen of $11 \times 5 \times 5 \mathrm{~cm}$, with a soft dark lesion, of $10 \mathrm{~cm}$ diameter, in the upper pole. Gross examination showed no haemorrhage or necrosis. Microscopic examination revealed a non capsulated spindle and polyhedral cell proliferation along with multiple foci of cellular necrosis. Tumor cells, with pleomorphic and atypic vesicular nuclei, showed marked pleomorphism and rare mitotic figures (Figure 1, 2). Immunohistochemistry showed that the neoplastic cells were positive for smooth muscle actin and for h-caldesmon and negative for CD34, calponin, FVIII-associated antigen, S100, EMA and cytokeratin AE1 AE3. There was left suprarenal gland and diaphragm involvement. The examined lymph nodes had no neoplastic infiltration. Diagnosis of locally advanced primary leiomyosarcoma of the spleen was made (Figure 1).

The patient underwent specific chemotherapic regimen (5 cycles) with epirubicin $90 \mathrm{mg}$ (days 1 and 2) and ifosfamide $2700 \mathrm{mg}$ (days $1-5$ ) every 21 days, with no significant adverse reactions.

Actually, 21 months after operation, the patient is alive and totally disease-free.

\section{Discussion}

Leiomyosarcoma is a rare tumour, predominantly localized in stomach, small intestine and retroperitoneum [1]. It is also described in genitourinary tract and inferior vena cava [2]. The aetiology is unknown, and the clinical presentation may be variable. The correct diagnosis is usually made at a late stage, with frequent metastatic spread to the liver (the most frequent), skin, bone, lung, brain and soft

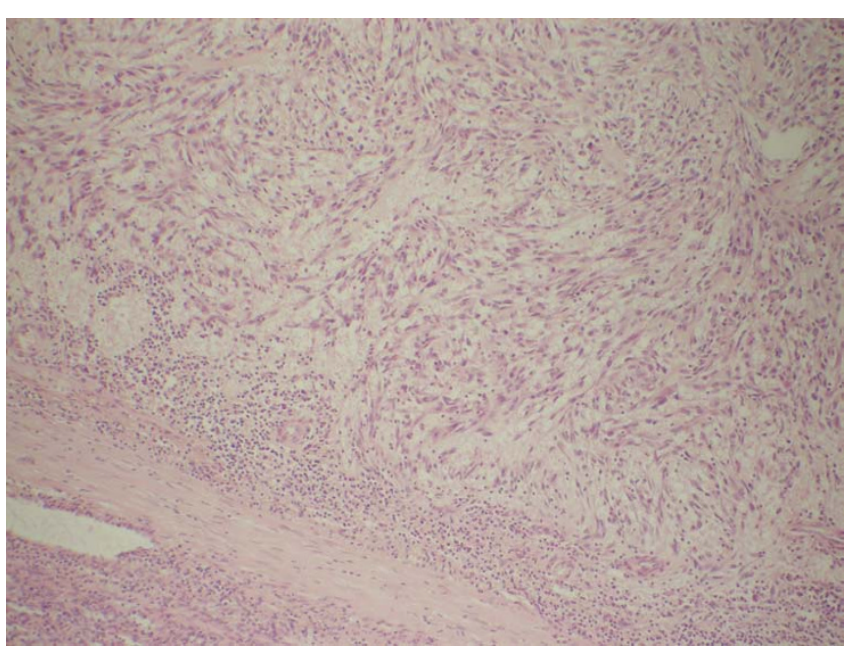

\section{Figure I}

histological finding of the removed spleen (hematoxylin eosin). Non capsulated spindle cells, with oedema and lymphocytic infiltration. No necrosis is present in this field.

tissue $[1,3]$. For this reason the prognosis of this tumour is poor. The most important criterion of malignancy are: number of mitotic figures present [4], high cellularity, atypia, large size and distant diffusion [1]. The most important prognostic factors for primary gastrointestinal leiomyosarcomas have been shown to be histologic grade, local invasiveness, and extent of resection [5]. A suspicious diagnosis can be obtained with US, CT scan and MRI with gadolinium, although diagnosis can be made only at laparotomy, after pathological examination of the removed specimen. The differential diagnosis include haemangioma, littoral cell angioma, lymphangioma,

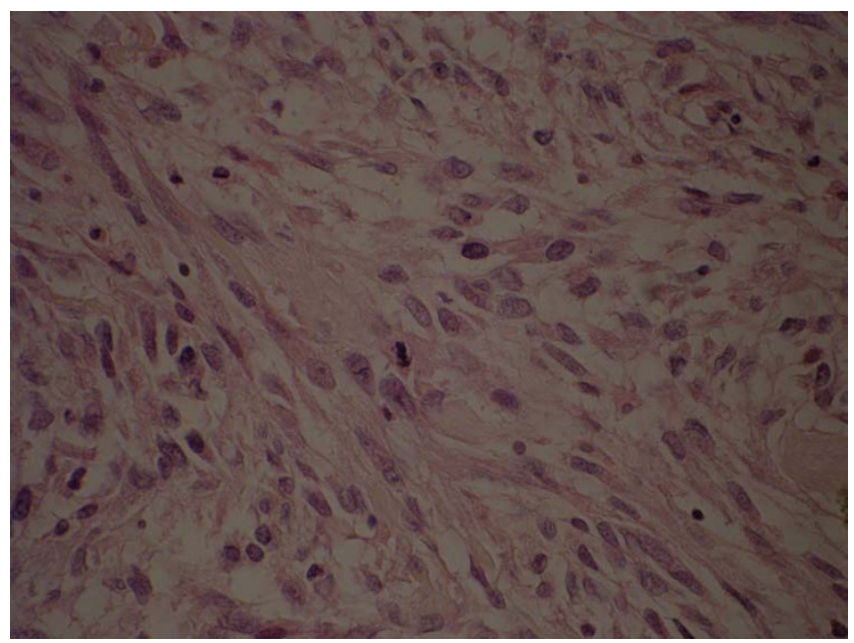

Figure 2

Photomicrograph showing moderate pleomorphism and rare mitosis are present ( $\times 40$ hematoxylin eosin). 
lymphoma, angiosarcoma, other rare sarcomas and metastases [6]. In our patient, diagnosis of spontaneous splenic haematoma or lymphoma was initially considered, due to the lack of other sign or symptoms. Primary human splenic localization of leiomyosarcoma, although described in canine spleens in 16 cases $[7,8]$, is described in only one case in literature [3]. The other case described demonstrated the poor prognosis of these tumours with early metastatic spreading. In our patient neither haematogenous spread nor lymph node involvement was seen, but only local infiltration of suprarenal left gland and diaphragm. The surgery was performed with a curative intent. In the other case splenectomy didn't seem to prevent metastatic diffusion. Due to the lack of cases, no specific chemotherapy regimen has been tested to provide a longer survival. However the use of chemotherapy regimen with activity in treating metastatic soft tissue sarcoma should be offered to these patients.

\section{Conclusion}

Leiomyosarcoma is a rare neoplasm, with a poor prognosis. Along with this case we have described, only one case of splenic localization is reported in literature. The diagnosis can be made only at laparotomy, after pathological examination of the removed specimen; US, CT scan and MRI can be useful in suspecting diagnosis. Splenectomy performed in early stage, without rupture, seems to improve survival. No specific chemotherapy regimen has been tested for this neoplasm, but adjuvant therapy should be offered to these patients, even if only for palliation.

\section{Competing interests}

The author(s) declare that they have no competing interests.

\section{Authors' contributions}

PP, preperation of the draft manuscript, VV, GC, MC, AC, Searching of the literature and helped in preperation of draft FT, RI, GC, AS, FR, LF, MAM, Helped in preperation of manuscript GB final revision of the manuscript.

All authors read and approved the final manuscript.

\section{Acknowledgements}

Written informed consent was obtained from the patient for publication of this case report.

\section{References}

I. Townsend C, Mattox KL, Evers MB, Beauchamp RD: Sabiston Textbook of Surgery. The biological basis of modern surgical practice. 17th edition. Philadelphia. Saunders ed; 2004.

2. Hines OJ, Nelson S, Quinones-Baldrich WJ, Eilber FR: Leiomyosarcoma of the inferior vena cava. Prognosis and comparison with leiomyosarcoma of other anatomic sites. Cancer 1999, 85: 1077-1083.

3. Daudia AT, Walker S, Morgan B, Lloyd DM: Leiomyosarcoma of the spleen. Surgery 200I, I30:893-894.
4. Golden T, Stout AP: Smooth muscle tumours of the gastrointestinal tract and retroperitoneal tissues. Surg Gynecol Obstet 1941, 73:784-810.

5. McGrath PC, Neifeld JP, Lawrence W, Kay S, Horsley JS, Parker JA: Gastrointestinal sarcomas: analysis of prognostic factors. Ann Surg 1987, 206:706-7I0.

6. $\mathrm{Ha} \mathrm{HK}, \mathrm{Kim} \mathrm{HH}$, Kim BK, Choi BI: Primary angiosarcoma of the spleen - CT and MR imaging. Acta Radiol 1994, 35:455-458.

7. Kapatkin AS, Mullen HS, Matthiesen DT, Patnaik AK: Leiomyosarcoma in dogs: 44 cases (1983-1988). J Am Vet Med Assoc 1992, 201:1077-1079.

8. Weinstein MJ, Carpenter JL, Schunk CJ: Nonangiogenic and nonlymphomatous sarcomas of the canine spleen: 57 cases (1975-1987). J Am Vet Med Assoc 1989, I 95:784-788.

\section{Publish with Biomed Central and every scientist can read your work free of charge}

"BioMed Central will be the most significant development for disseminating the results of biomedical research in our lifetime. " Sir Paul Nurse, Cancer Research UK

Your research papers will be:

- available free of charge to the entire biomedical community

- peer reviewed and published immediately upon acceptance

- cited in PubMed and archived on PubMed Central

- yours - you keep the copyright

Submit your manuscript here:

http://www.biomedcentral.com/info/publishing_adv.asp
Biomedcentral 